\title{
Regional blood flows are affected differently by PEEP when the abdomen is open or closed: an experimental rabbit model
}

\section{[L'influence de la PEP sur le débit sanguin régional est différente selon que l'abdomen est fermé ou ouvert : un modèle expérimental chez le lapin]}

Jean-Yves Lefrant MD PhD, ${ }^{*}$ Jean-Marie Juan MD, $\dagger$ Pascal Bruelle MD MSc, ${ }^{*}$ Roland Demaria MD PhD, $\dagger$ Robert Cohendy MD PhD,$\dagger$ Guy Aya MD MSc, $\dagger$ Marie-Claire Oliva-Lauraire, $\dagger$ Pascale Peray MD PhD, $\ddagger$ Emmanuelle Robert PhD, $\dagger$ Jean-Emmanuel de La Coussaye MD PhD, * Jean-Jacques Eledjam MD PhD, * Michel Dauzat MD PhD $\dagger$

Objective: The study of induced circulatory changes requires simultaneous assessment of multiple regional circulations because of interactions and compensatory mechanisms. Positive end expiratory pressure mechanical ventilation (PEEP) is known to cause marked, and potentially deleterious, cardiovascular changes. Our aim was to use a comprehensive approach to assess PEEP-induced circulatory changes in open vs closed abdomen animals.

Material and methods: In the anesthetized rabbit, we used implantable Doppler micro-probes to measure blood flow simultaneously in the ascending aorta, inferior vena cava, portal vein, hepatic artery, common carotid artery, and renal artery. We studied spontaneously breathing animals (Group A), and open (Group B) and closed abdomen (Group $C$ ) animals mechanically ventilated at $\mathrm{O}$ (ZEEP) and $12 \mathrm{~cm} \mathrm{H}_{2} \mathrm{O}$ PEEP.

Results: In Group A, all biological and hemodynamic variables remained unchanged for three hours at the end of the surgical procedure. In Groups B and C, ZEEP produced no significant hemodynamic change. PEEP induced a decrease in carotid, hepatic, and renal artery blood flow in Groups B and C, a decrease in heart rate and mean arterial blood pressure in Group B, and a decrease in aorta blood flow in Group C.

Conclusions: These experimental results demonstrate the usefulness of the comprehensive approach of circulatory changes, and confirm that PEEP may have deleterious effects on regional blood flow, even without significant change in cardiac output, especially when the abdomen is open.
Objectif : L'étude de changements circulatoires induits exige une évaluation simultanée de multiples circulations régionales à cause des interactions et des mécanismes compensateurs. La ventilation mécanique à pression télé-expiratoire positive (PTEP) cause des modifications cardio-vasculaires marquées, potentiellement nocives. Nous évaluons, selon une démarche globale, les changements circulatoires induits par la PTEP dans un abdomen animal ouvert vs fermé.

Méthode : Nous avons utilisé, chez un lapin anesthésié, des microsondes Doppler implantables pour mesurer le débit sanguin simultanément dans l'aorte ascendante, la veine cave inférieure, la veine porte, l'artère hépatique, l'artère carotide commune et l'artère rénale. Nous avons observé les animaux en respiration spontanée (Groupe A), et des animaux à l'abdomen ouvert (Groupe B) ou fermé (Groupe C) sous ventilation mécanique à O (ZEP) et $12 \mathrm{~cm} \mathrm{H}_{2}$ OPTEP.

Résultats : Dans le Groupe A, toutes les variables biologiques et hémodynamiques sont demeurées inchangées pendant trois heures après la fin de l'intervention chirurgicale. Dans les Groupes B et C, la ZEP n'a produit aucun changement hémodynamique significatif. La PTEP a provoqué une baisse du débit sanguin artériel carotide, hépatique et rénal chez les lapins des Groupes B et $C$, une baisse de la fréquence cardiaque et de la tension artérielle moyenne chez ceux du Groupe $B$ et une baisse du débit sanguin aortique chez ceux du Groupe C.

Conclusion : Ces résultats expérimentaux démontrent l'utilité d'aborder globalement les changements circulatoires et confirment que la PTEP peut provoquer des effets nocifs sur le débit sanguin régional, même sans modification significative du débit cardiaque, surtout lorsque l'abdomen est ouvert.

From the Department of Anesthesiology, Critical Care Medicine, and Emergency, ${ }^{*}$ Nîmes University Hospital; the Laboratory of CardioVascular Physiology and Anesthesiology, $†$ Montpellier-Nimes Faculty of Medicine; and the Department of Medical Information, Biostatistics, and Epidemiology, † Nîmes University Hospital, Nîmes, France. Address correspondence to: Dr. Michel Dauzat, Montpellier-Nîmes Faculty of Medicine, Avenue Kennedy, 30907 Nîmes cedex, France. Phone: +33 (0)4 662349 73; Fax: +33 (0)4 662355 38; E-mail: dauzat@sc.univ-montpl.fr Accepted for publication August 20, 2001. Revision accepted December 17, 2001. 


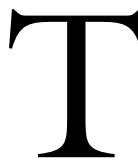

$\mathrm{H}$ E effects of mechanical ventilation (MV) on regional blood circulations have been evaluated, but most studies focused on a single variable or circulation, regardless of interactions and compensatory mechanisms that should require the simultaneous assessment of multiple regional circulations. Positive end expiratory pressure (PEEP) causes a decrease in cardiac output $(\mathrm{CO})$ by compressing the pulmonary vascular bed, thus increasing right ventricular afterload, impeding its emptying, and decreasing left ventricular preload. ${ }^{1}$ By increasing intrathoracic pressure, PEEP may impede venous return, ${ }^{2}$ but Fessler et al., ${ }^{3}$ and Takata and Robotham, ${ }^{4}$ demonstrated in an animal model that PEEP also increases the intra-abdominal pressure around the abdominal vasculature. Therefore the pressure gradient for venous return is not reduced by PEEP, especially in patients with hypervolemia. ${ }^{5}$ The fall in $\mathrm{PaCO}_{2}$ with controlled ventilation leads to a decrease in cardiac index as well as cerebral and peripheral vasoconstriction. Peripheral organ perfusion may also be altered by local pressure changes and/or circulatory interactions. Hepatic blood flow is reduced proportionally to the level of PEEP but the relative role of the $\mathrm{CO}$ decrease and of the splanchnic vasoconstriction induced by the fall in $\mathrm{PaCO}_{2}$ remains unclear, since $\mathrm{CO}, \mathrm{PaCO}_{2}$ and hepatic blood flow were not measured simultaneously. ${ }^{6-9}$ Renal blood flow is also reduced by PEEP mainly because of the sympathetic activation associated with increased plasma renin activity. ${ }^{10}$ Studies evaluating the effect of PEEP on cerebrovascular circulation were performed in patients suffering from head trauma, without discriminating the effects of PEEP from those of MV.

Therefore, the understanding of PEEP induced circulatory changes requires the simultaneous assessment of multiple regional circulations, in correlation with blood pressure, heart rate, and arterial blood gases. We used this approach to assess the hemodynamic changes induced by MV and PEEP, in open $v s$ closed abdomen anesthetized rabbits.

Material and methods

Animal preparation and anesthesia

Twenty-three white New Zealand rabbits on a normal diet, weighing between 3 and $4 \mathrm{~kg}$, were submitted to the experiment. The animal care complied with the "Principles of Laboratory Animal Care", as formulated by the National Society for Medical Research, and the "Guide for the Care and Use of Laboratory Animals" of the National Academy of Sciences (National Academy Press, Washington, DC, USA, 1996).
Premedication consisted of the $i m$ injection of ketamine $50 \mathrm{mg} \cdot \mathrm{kg}^{-1}$. A fluid filled catheter was introduced in an ear vein, and the animal was anesthetized in the supine position with iv ketamine (bolus 10 $\mathrm{mg} \cdot \mathrm{kg}^{-1}$ followed by constant infusion at 0.1 $\left.\mathrm{mg} \cdot \mathrm{kg}^{-1} \cdot \mathrm{min}^{-1}\right)$, and intubated with a cuffed endotracheal tube. Transperitoneal fluid loss was compensated by the continuous infusion of saline at a rate of 10 $\mathrm{mL} \cdot \mathrm{kg} \cdot{ }^{-1} \cdot \mathrm{hr}^{-1}$.

The electrocardiogram (CP110 ECG monitor, Philips, Eindhoven, the Netherlands) was monitored continuously from electrodes inserted in the limbs, and the output signal was digitized and displayed on a polygraph. A fluid filled catheter was introduced into the right femoral artery to monitor blood pressure and to sample arterial blood. Arterial pressure was measured with a Gould P23 ID pressure probe and DA 100 transducer amplifier (Biopac Systems, Santa Barbara, CA, USA), then digitized and displayed on the polygraph. Zero reference level for arterial pressure was defined as the mid-thoracic level.

Esophageal pressure was monitored through a fluid filled catheter connected to a P23 ID pressure transducer (Gould Statham, USA), and a DA 100 transducer amplifier. This catheter was positioned while the rabbit was breathing spontaneously in order to obtain a maximal decrease of the esophageal pressure with inspiration. Zero reference level for esophageal pressure was defined as the mid thoracic level. All pressure transducers were calibrated against a mercury column.

Rectal temperature was measured continuously, and a temperature controlled heating pad prevented hypothermia (Harvard Homeothermic Blanket Unit, Harvard, Edenbridge, UK).

\section{Surgical procedures}

DBF and HDP $20 \mathrm{MHz}$ implantable Doppler probes (Crystal Biotech, Hopkinton, MA, USA) of adapted diameter were used for blood flow measurement. The chest was opened by transecting the clavicle and the first three ribs on the left side of the sternum, without pleural opening, and Doppler probes were placed around the ascending aorta and the left common carotid artery. The right renal artery was dissected through a right subcostal incision, and a Doppler probe was placed around the vessel. The hepatic artery was then dissected away from the portal vein, downstream from the bifurcation of the common hepatic artery. A Doppler probe was placed around the proper hepatic artery. After incision of the periportal fat tissue, a Doppler probe was placed on the main portal vein $10 \mathrm{~mm}$ upstream from its bifurcation. The inferior vena cava blood flow was measured with a Doppler 
probe placed just downstream from the renal veins. Doppler transducers were connected to a CBI 8000 (Crystal Biotech, Hopkinton, MA, USA) eight channel sonometry system operating in pulsed Doppler mode at $20 \mathrm{MHz}$ emitting frequency and $125 \mathrm{kHz}$ pulse repetition frequency. Crystal Biotech PD-20 Pulsed Doppler modules were used for venous blood flow measurement, and Crystal Biotech HVPD-20 Pulsed Doppler modules (high PRF, anti-aliasing modules for high velocity measurement) were used for arterial blood flow measurement. Each Doppler channel was calibrated for the probe diameter.

At the end of the surgical procedure, the thorax was closed. The abdomen was left open in Groups A and $\mathrm{B}$, and was closed in Group C.

\section{Polygraph recording}

ECG, arterial and esophageal pressure, as well as Doppler signals from the aorta, inferior vena cava, carotid, renal, and hepatic arteries, and portal vein were digitized (MP100 system, Biopac Systems, Santa Barbara, CA, USA) and displayed as a polygraph. Calculation, display, and storage were achieved with the Acqknowledge V3.2 software (Biopac Systems, Santa Barbara, CA, USA), on a personal computer.

Blood flow velocity curves were monitored continuously since their systolic modulation ensured the correct positioning of the probe on arteries. The time averaged mean arterial or venous blood flow, as well as mean arterial pressure, were calculated by the Acqknowledge software on eight-second samples selected by two independent investigators.

\section{Protocol}

At the end of the surgical procedure, a 45-min stabilization period was allowed, after which stability was assumed if all variables remained unchanged over a 15-min period. Arterial blood gases and hematocrit were measured, and the rectal temperature was recorded $\left(\mathrm{T}_{0}\right)$.

Seven rabbits breathing spontaneously oxygenenriched air through a facial mask served as controls (Group A). The systemic (heart rate, mean arterial pressure, aortic and caval blood flow, rectal temperature) and regional (carotid, renal, hepatic artery, and portal vein blood flow) variables were monitored continuously and recorded every $60 \mathrm{~min}$ for $180 \mathrm{~min}$. Arterial blood gases and hematocrit level were measured every hour during the session.

In Group B, ten rabbits received vecuronium bromide $\left(0.5 \mathrm{mg} \cdot \mathrm{kg}^{-1}\right)$ to ensure neuromuscular blockade, immediately after $\mathrm{T}_{0}$, and were ventilated mechanically (Servo 900 C, Siemens-Elema, Sweden) with 100\%
$\mathrm{FIO}_{2}$, frequency 40 breaths. $\mathrm{min}^{-1}$, controlled pressure $20 \mathrm{~cm} \mathrm{H}_{2} \mathrm{O}$, and zero end expiratory pressure (ZEEP). These variables were chosen to ensure zero end inspiratory and expiratory flows. After $20 \mathrm{~min}$, all variables were measured $\left(\mathrm{T}_{1}\right)$. Thereafter, $4-\mathrm{cm} \mathrm{H}_{2} \mathrm{O}$ increments of PEEP levels were introduced every 20 min until 12 $\mathrm{cm} \mathrm{H}_{2} \mathrm{O}$ PEEP was reached $\left(\mathrm{T}_{2}\right)$. Then, the PEEP level was returned to ZEEP and the last measurements were performed after a 20- min stability period $\left(\mathrm{T}_{3}\right)$.

Air flow and pressure curves were obtained from the ventilator, digitized and displayed on the polygraph to ascertain that preset pressures were transmitted to the rabbit's lungs. Arterial pressure, aortic, carotid, renal, hepatic, portal, and caval blood flow, as well as esophageal pressure, were recorded. Arterial blood gases and hematocrit were measured $20 \mathrm{~min}$ after each change in the level of PEEP.

In Group C, six rabbits were managed as in Group $\mathrm{B}$, but the abdominal wound was closed immediately after the surgical procedure.

\section{Statistical analysis}

Blood gases and respiratory variables are presented as median values with $25^{\text {th }}$ and $75^{\text {th }}$ percentiles. In all groups, blood flow data are presented as relative changes of the median from $\mathrm{T}_{0}$. In Groups $\mathrm{B}$ and $\mathrm{C}$, changes in respiratory variables were expressed relatively to $T_{1}$. Intragroup differences were tested by a global Friedmann test. When this test yielded significant results, a two-by-two Dunn's post-test was applied. Differences between Groups B and C regarding changes from $\mathrm{T}_{0}$ were evaluated by unpaired $t$ tests. Correlation between arterial pressure, aortic blood flow, $\mathrm{PaCO}_{2}$ and mean hepatic, carotid, and renal blood flow changes were tested by Spearman analysis. Results were considered significant when $P<0.05$.

Statistical calculations were performed using GraphPad Prism V3.0 for Windows (GraphPad Software, San Diego, California, USA).

Results

Group A (controls)

All biological and hemodynamic variables (Table I) remained stable for three hours at the end of the surgical procedure except for a slight decrease in $\mathrm{PaCO}_{2}$.

\section{Effects of mechanical ventilation and PEEP in open abdomen rabbits (Group B)}

In open abdomen rabbits, mechanical ventilation at ZEEP $\left(T_{1}\right)$ produced no change in systemic and regional hemodynamic variables (Table II, Figure 1), whereas $\mathrm{PaCO}_{2}$ decreased and $\mathrm{pH}$ increased slightly at $\mathrm{T}_{1}(P<0.001)$. 
TABLE I Systemic variables at $\mathrm{T}_{\mathrm{f}}$ in the three groups (median $25^{\mathrm{th}}-75^{\mathrm{th}}$ percentile)

\begin{tabular}{|c|c|c|c|}
\hline Parameter & $\begin{array}{l}\text { Group A } \\
\text { Controls }\end{array}$ & $\begin{array}{l}\text { Group B } \\
\text { Open abdomen }\end{array}$ & $\begin{array}{l}\text { Group C } \\
\text { Closed abdomen }\end{array}$ \\
\hline $\mathrm{pH}$ & $7.36(7.30-7.39)$ & $7.33(7.32-7.35)$ & $7.26(7.22-7.32)$ \\
\hline $\mathrm{PaO}_{2}(\mathrm{mmHg})$ & $361(333-412)$ & $318(256-397)$ & $262(222-332)$ \\
\hline $\mathrm{PaCO}_{2}(\mathrm{mmHg})$ & $41.5(39.5-44.2)$ & $28(26-34)$ & $33.5(32.7-34.5)$ \\
\hline Hematocrit (\%) & $30(28-32)$ & $28(28-29)$ & $30(29-31)$ \\
\hline Mean arterial pressure $(\mathrm{mmHg})$ & $79(73-86)$ & $73(69-78)$ & $66.5(65.7-68.4)$ \\
\hline Heart rate (beats. $\min ^{-1}$ ) & $188(174-194)$ & $189(169-203)$ & $190(179-211)$ \\
\hline
\end{tabular}

TABLE II Relative changes of hemodynamic variables (from $\mathrm{T}_{0}$ ) in the three groups (median $25^{\text {th }}-75^{\text {th }}$ percentile)

\begin{tabular}{|c|c|c|c|}
\hline & $T_{1}$ & $T_{2}$ & $T_{3}$ \\
\hline A-Controls & SV & SV & SV \\
\hline Mean arterial pressure & $0.51 \quad(0.40-1.19)$ & $0.59 \quad(0.33-1.10)$ & $0.61 \quad(0.45-1.08)$ \\
\hline Heart rate & $(0.92-1.03)$ & $0.97 \quad(0.94-1.08)$ & $0.94 \quad(0.88-0.99)$ \\
\hline Aorta flow & $0.82 \quad(0.71-0.95)$ & $0.88 \quad(0.74-0.93)$ & $0.89 \quad(0.58-1.17)$ \\
\hline Inferior vena cava flow & $0.98 \quad(0.69-1.89)$ & $0.96(0.69-1.28)$ & $0.83(0.52-1.23)$ \\
\hline Portal vein flow & $1 \quad(0.96-1.20)$ & $1.06 \quad(0.92-3.83)$ & $1.25 \quad(0.82-3.17)$ \\
\hline Renal artery flow & $0.85 \quad(0.50-1.26)$ & $0.90 \quad(0.54-1.33)$ & $0.83 \quad(0.60-1.24)$ \\
\hline Hepatic artery flow & $0.51 \quad(0.40-1.19)$ & $0.59 \quad(0.33-1.09)$ & $0.61 \quad(0.45-1.08)$ \\
\hline Carotid artery flow & $0.95 \quad(0.73-1.21)$ & $0.86 \quad(0.68-1.28)$ & $0.73 \quad(0.71-1.10)$ \\
\hline B - Open abdomen & MV - ZEEP & MV - PEEP & MV - ZEEP \\
\hline Mean arterial pressure & $0.98 \quad(0.93-1.04)$ & $0.39 \quad(0.34-0.44)$ & $0.94 \quad(0.83-1.07)$ \\
\hline Heart rate & $1 \quad(0.95-1.02)$ & $0.88 \quad(0.81-0.94)$ & $0.97 \quad(0.91-1.04)$ \\
\hline Aorta flow & $0.91 \quad(0.81-1.08)$ & $0.45 \quad(0.32-0.58)$ & $0.89 \quad(0.62-1.09)$ \\
\hline Inferior vena cava flow & $0.88 \quad(0.83-0.93)$ & $1.06 \quad(0.87-1.38)$ & $0.83 \quad(0.62-0.98)$ \\
\hline Portal vein flow & $1.05 \quad(0.88-1.36)$ & $1.02(0.75-1.22)$ & $1.18 \quad(0.71-1.30)$ \\
\hline Renal artery flow & $1.13(0.57-1.19)$ & $0.06 \quad(0.02-0.40)$ & $0.39 \quad(0.00-0.53)$ \\
\hline Hepatic artery flow & $0.77 \quad(0.64-0.90)$ & $0.07 \quad(0.00-0.15)$ & $0.32 \quad(0.15-0.47)$ \\
\hline Carotid artery flow & $0.88 \quad(0.81-1.05)$ & $0.32 \quad(0.28-0.44)$ & $0.64 \quad(0.54-0.81)$ \\
\hline$C-$ Closed abdomen & MV - ZEEP & MV - PEEP & MV - ZEEP \\
\hline Mean arterial pressure & $0.91 \quad(0.90-0.92)$ & $0.48 \quad(0.38-0.63)$ & $1.20 \quad(1.12-1.28)$ \\
\hline Heart rate & $1.01 \quad(0.98-1.05)$ & 1.14 (1.09-1.17) & $1.05 \quad(0.02-1.12)$ \\
\hline Aorta flow & $0.87 \quad(0.81-0.93)$ & $0.52 \quad(0.47-0.58)$ & $0.93(0.81-1.02)$ \\
\hline Inferior vena cava flow & $0.89 \quad(0.81-0.98)$ & $1.08 \quad(0.75-1.26)$ & $0.83 \quad(0.76-0.98)$ \\
\hline Portal vein flow & $0.91 \quad(0.82-0.98)$ & $1.02(0.95-1.11)$ & $0.99(0.88-1.05)$ \\
\hline Renal artery flow & $0.95 \quad(0.94-0.97)$ & $0.48 \quad(0.27-0.61)$ & $0.83 \quad(0.70-0.86)$ \\
\hline Hepatic artery flow & $0.77 \quad(0.60-0.97)$ & $0.31 \quad(0.11-0.50)$ & $0.68 \quad(0.62-0.80)$ \\
\hline Carotid artery flow & $1.05 \quad(0.95-1.08)$ & $0.69 \quad(0.57-0.78)$ & $0.87 \quad(0.82-1.03)$ \\
\hline
\end{tabular}

$\mathrm{SV}=$ spontaneous ventilation; $\mathrm{MV}=$ mechanical ventilation; $\mathrm{ZEEP}=$ zero end expiratory pressure; $\mathrm{PEEP}=$ positive $\left(20 \mathrm{~cm} \mathrm{H}_{2} \mathrm{O}\right)$ end expiratory pressure.

$\mathrm{pH}$ decreased at $\mathrm{T}_{2}(P<0.00 \mathrm{l})$ and $\mathrm{T}_{3}(P<0.01)$, while $\mathrm{PaCO}_{2}$ increased at $\mathrm{T}_{2}(P<0.001)$, and $\mathrm{T}_{3}(P<$ $0.001)$, but $\mathrm{pH}$ and $\mathrm{PaCO}_{2}$ were not significantly different from $\mathrm{T}_{0}$ at $\mathrm{T}_{3}$.

At $\mathrm{T}_{2}$, PEEP induced an increase in ventilatory pressure associated with a decrease in ventilatory volumes. There was a slight decrease in heart rate $(P<0.05)$, and a more marked decrease in mean arterial pressure $(P<$ $0.001)$. There was no significant change in aorta, inferior vena cava, and portal vein time averaged blood flow with PEEP. Carotid and renal artery blood flow $(P<$ $0.001)$, as well as hepatic artery blood flow $(P<0.01)$ decreased at $\mathrm{T}_{2}$. All but the hepatic artery $(P<0.001)$ blood flows returned to their $T_{1}$ values when PEEP was reduced to $\operatorname{ZEEP}\left(\mathrm{T}_{3}\right)$; (Figure 1 ).

The changes in hepatic, renal, and carotid artery blood flow were not correlated to the changes in aortic blood flow, arterial pressure, or $\mathrm{PaCO}_{2}$. 
Effects of mechanical ventilation and PEEP in closed abdomen rabbits (Group C)

In closed abdomen rabbits, $\mathrm{PaCO}_{2}$ decreased and $\mathrm{pH}$ increased slightly at $\mathrm{T}_{1}(P<0.001)$.

PEEP induced an increase in ventilatory pressure associated with a decrease in ventilatory volumes. There was no significant change in heart rate, and the decrease in mean arterial pressure was significant only between $\mathrm{T}_{2}$ and $\mathrm{T}_{3}$. Aorta $(P<0.01)$, carotid artery $(P$ $<0.05)$, hepatic artery $(P<0.001)$, and renal artery $(P<0.01)$ blood flow decreased. All variables but $\mathrm{PaCO}_{2}(P<0.01)$ were not significantly different from their $\mathrm{T}_{0}$ values when PEEP was reduced to $\operatorname{ZEEP}\left(\mathrm{T}_{3}\right)$ (Table II, Figure 2).

\section{Differences between Groups B and $C$}

The changes in heart rate from $\mathrm{T}_{1}$ to $\mathrm{T}_{2}$ and in mean arterial pressure from $T_{1}$ to $T_{3}$ were statistically significant. The decrease in $\mathrm{pH}$ from $\mathrm{T}_{1}$ to $\mathrm{T}_{2}$ was greater in Group C than in Group B, while the changes in $\mathrm{PaCO}_{2}$ from $\mathrm{T}_{1}$ to $\mathrm{T}_{2}$ were significant. Changes from $\mathrm{T}_{1}$ of the other variables were not significant.

\section{Discussion}

Our animal model of multiple regional blood flows was shown to be stable throughout a three-hour period. MV at ZEEP had no effect on hemodynamic variables in open as well as in closed abdomen animals. Mean arterial blood pressure decreased with PEEP, more significantly in open than in closed abdomen animals, while heart rate decreased in open but not in closed abdomen animals. Carotid, renal, and hepatic arterial blood flow decreased with PEEP in open and in closed abdomen animals, without significant correlation with $\mathrm{CO}$ or $\mathrm{PaCO}_{2}$ changes. The decrease in aortic blood flow with PEEP was significant only in closed abdomen animals. All variables but hepatic blood flow returned to their basal values when end expiratory pressure was reduced to zero.

\section{Effects of PEEP on systemic hemodynamics}

In our study, the net effect of PEEP was a decrease in mean arterial blood pressure, especially in open abdomen animals. In the rabbit, the decrease in mean arterial blood pressure during PEEPll is explained by a decrease in cardiac output, ${ }^{12}$ a reflex decrease in autonomic tone and, at high lung volume, an increase in pulmonary vascular resistance and a direct mechanical interaction with the heart in a way that limits absolute cardiac volume. ${ }^{13}$ In our study, the fall in cardiac output, reflected by aortic blood flow, was significant only in closed abdomen animals. Although we didn't measure abdominal pressure, we can assume

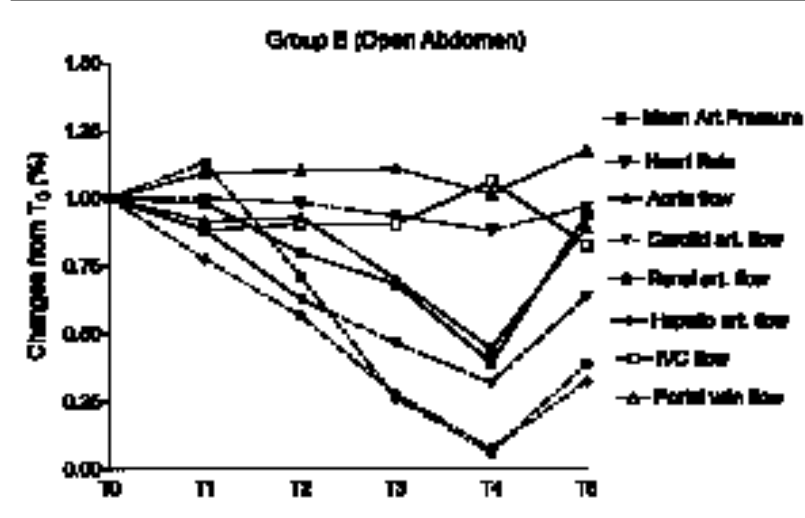

FIGURE 1 Hemodynamic variables (relative changes of the median from $\mathrm{T}_{0}$ ) during PEEP in Group $\mathrm{B}$ (open abdomen). $\mathrm{T}_{0}=$ end of the stabilization period; $\mathrm{T}_{1}=$ zero end expiratory pressure (ZEEP); $\mathrm{T}_{2}=$ positive end expiratory pressure (PEEP) of 12 $\mathrm{cm} \mathrm{H}_{2} \mathrm{O} ; \mathrm{T}_{3}=$ zero end expiratory pressure (ZEEP); IVC=inferior vena cava.

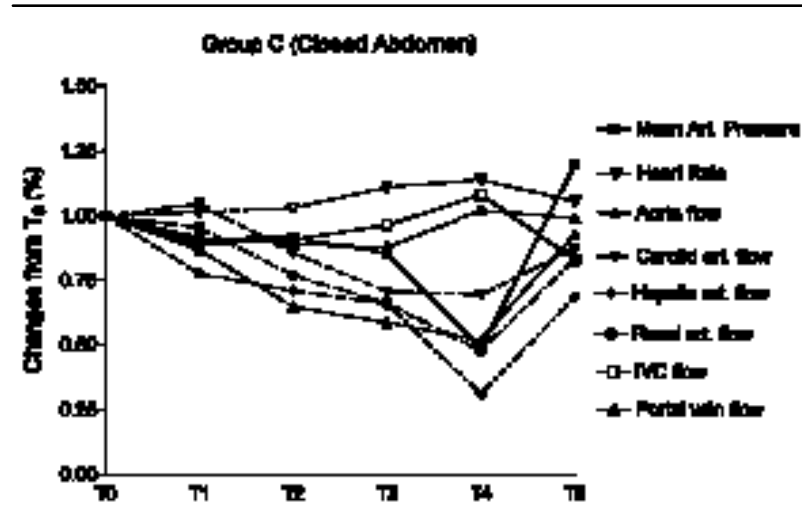

FIGURE 2 Hemodynamic variables (relative changes of the median from $\mathrm{T}_{0}$ ) during positive end expiratory pressure (PEEP) in Group C (closed abdomen). $\mathrm{T}=$ end of the stabilization period; $\mathrm{T}_{1}=$ zero end expiratory pressure $(\mathrm{ZEEP}) ; \mathrm{T}_{2}=$ positive end expira-

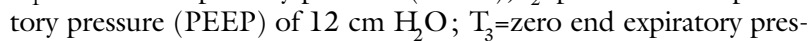
sure $(\mathrm{ZEEP})$; IVC=inferior vena cava.

that it was higher in closed than in open abdomen animals, whereas lung inflation was higher in open abdomen animals. Conversely, the fall in mean arterial blood pressure was associated with a decrease in heart rate only in open abdomen animals. As lung inflation was limited in closed abdomen animals, the inflation-vasodilatation reflex ${ }^{13}$ may have contributed to the greater fall in mean arterial blood pressure and heart rate in the open abdomen animal. 


\section{Effects of PEEP on carotid blood flow}

PEEP, but not mechanical ventilation in itself, produced a decrease in common carotid blood flow. In patients with severe head trauma, mechanical ventilation alters the venous return from the brain, inducing an increase in intracranial pressure and a decrease in cerebral blood flow. ${ }^{14}$ In physiological conditions, autoregulation of cerebral blood flow should limit the decrease in cerebral blood flow. Conversely, the decrease in $\mathrm{PaCO}_{2}$ at $\mathrm{ZEEP}$, and its increase during PEEP, could have induced, respectively, cerebral vasoconstriction and relaxation, but $\mathrm{PaCO}_{2}$ remained low after the onset of mechanical ventilation. Therefore, the decrease in carotid blood flow may have been the combined result of decreased arterial blood pressure, increased venous pressure, and hypocapnia. For technical reasons, we measured only common carotid blood flow but neither internal carotid artery blood flow nor intracranial pressure. Therefore, our results do not allow a definitive conclusion in this regard.

\section{Effects of PEEP on hepatic artery and portal vein blood flow}

Bonnet et al., ${ }^{7}$ reported a decrease in hepatic blood flow with PEEP correlated to the decrease in CO, but these authors did not measure the mean arterial blood pressure. Hugues et al. ${ }^{9}$ suggested a correlation with the fall in arterial $\mathrm{PaCO}_{2}$ whereas others attributed the reduction to an increase in hepatic vascular resistance. ${ }^{15}$ We observed a decrease in hepatic artery blood flow without significant change in portal vein blood flow during PEEP, in open and in closed abdomen animals, and without correlation with $\mathrm{CO}$ or $\mathrm{PaCO}_{2}$ changes. The hepatic arterial buffer response by which an increase in portal vein blood flow elicits hepatic artery constriction ${ }^{16}$ can probably not explain the marked decrease in hepatic artery blood flow we observed since portal vein blood flow rose non significantly and only in open abdomen animals. For Fujita, ${ }^{17}$ high levels of PEEP are associated with a decrease in hepatic blood flow and oxygen supply along with hepatic congestion. This was possible, although not measured, in open abdomen animals, but probably limited by the rise in abdominal pressure in closed abdomen animals.

\section{Effects of PEEP on renal artery blood flow}

Renal blood flow was altered significantly by high PEEP levels, as reported by others. ${ }^{18-21}$ These authors suggested that some reflex vasoconstriction mechanism involving sympathetic activation, and high plasma renin activity, was induced by PEEP and may explain the decrease in renal function. ${ }^{18,19}$

\section{Limitations of this study}

The measurement of cardiac output by the means of an ultrasonic Doppler probe positioned on the ascending aorta has been demonstrated to be as accurate as the thermodilution technique. ${ }^{22-24} \mathrm{We}$ used high pulse repetition frequency pulsed Doppler modules for blood flow measurement in small arteries, in order to avoid the aliasing phenomenon that could have resulted in unreadable graphs or false values. Nevertheless, although implanted Doppler probes are widely used for volume blood flow measurement in physiological studies, there are some causes of error. Firstly, not unlike electromagnetic blood flow measurement, pulsed Doppler ultrasound requires the use of fixed diameter probes. Therefore, vasodilatation is not allowed at the exact site of measurement, and the velocity profile may be altered when flow volume increases. This is not a problem with small diameter vessels, since the sample volume covers a large part of the vessel diameter. Conversely, changes in flow velocity profile, from parabolic to flat, may result in underestimation of the flow volume in large vessels, where the Doppler sample volume encompasses only a small portion of the vessel lumen. This effect is minimized when the chosen probe diameter is slightly lower than the vessel diameter in basal conditions.

A thorough evaluation of the venous return to the heart requires the measurement of superior as well as inferior vena cava blood flow. This was not feasible in our study, since this would have implied a large chest opening, with major consequences on ventilation and thoracic pressure.

\section{Conclusion}

Our model of anesthetized rabbits allowed the study of multiple regional blood circulations in the presence or absence of PEEP. Such a model may be highly valuable whenever circulatory interactions and compensation mechanisms are involved. Our study confirms most findings reported in the literature concerning the hemodynamic effects of mechanical ventilation with PEEP. Although mechanical ventilation induced a fall in $\mathrm{PaCO}_{2}$, and may have induced cerebral and peripheral vasoconstriction, this fall was partly reduced by PEEP, so that hypocapnia could not explain the decrease in carotid, renal, and hepatic artery blood flow observed in open as well as in closed abdomen animals. In the closed abdomen rabbit, a situation analogous to the nonsurgical setting, there was no decrease in heart rate, but aorta blood flow decreased, as did carotid, renal, and hepatic artery blood flow. In open abdomen animals, a situation analogous to the surgical setting, there was a marked decrease in arter- 
ial pressure. In this setting, a lower intra-abdominal pressure may result in larger splanchnic blood pooling, whereas larger lung inflation may induce reflex peripheral vasodilatation, worsening the fall in arterial pressure. Our results, in an experimental rabbit model, demonstrate the interest of the multiple circulation approach, and confirm that PEEP may have deleterious effects on regional blood flow, even when there is no significant change in cardiac output, especially when the abdomen is open.

\section{References}

1 Pinsky MR. Cardiovascular effects of ventilatory support and withdrawal. Anesth Analg 1994; 79: 567-76.

2 Berglund JE, Haldèn E, Jakobson S. Maintained cardiac output during positive end-expiratory pressure ventilation in open-chest pigs. Acta Anaesthesiol Scand 1997; 41: 618-23.

3 Fessler HE, Brower RG, Wise RA, Permutt S. Effects of positive end-expiratory pressure on the canine venous return curve. Am Rev Respir Dis 1992; 146: 4-10.

4 Takata M, Robotham JL. Effects of inspiratory diaphragmatic descent on inferior vena caval venous return. J Appl Physiol 1992; 72: 597-607.

5 Qvist J, Pontoppidan H, Wilson RS, Lowenstein E, Laver $M B$. Hemodynamic responses to mechanical ventilation with PEEP: the effect of hypervolemia. Anesthesiology 1975; 42: 45-55.

6 Sha M, Saito $\Upsilon$, Yokoyama K, Sawa T, Amaha K Effects of continuous positive-pressure ventilation on hepatic blood flow and intrahepatic oxygen delivery in dogs. Crit Care Med 1987; 15: 1040-3.

7 Bonnet F, Richard C, Glaser P, Lafay M, Guesde R Changes in hepatic flow induced by continuous positive pressure ventilation in critically ill patients. Crit Care Med 1982; 10: 703-5.

8 Winsö O, Biber B, Gustavsson B, Holm C, Milsom I, Niemand D. Portal blood flow in man during graded positive end-expiratory pressure ventilation. Intensive Care Med 1986; 12: 80-5.

9 Hughes RL, Mathie RT, Fitch W, Campbell D Liver blood flow and oxygen consumption during hypocapnia and IPPV in the greyhound. J Appl Physiol 1979; 47: 290-5.

10 Farge D, De La Coussaye JE, Beloucif S, Fratacci MD, Payen DM. Interactions between hemodynamic and hormonal modifications during PEEP- induced antidiuresis and antinatriuresis. Chest 1995; 107: 1095-100.

11 Stinnett $H O$. Altered cardiovascular reflex responses during positive pressure breathing. Fed Proc 1981; 40: 2182-7.

12 Schuster S, Erbel R, Weilemann LS, et al. Hemodynamics during PEEP ventilation in patients with severe left ventricular failure studied by transesophageal echocardiography. Chest 1990; 97:

1181-9.

13 Pinsky MR, Guimond J-G. The effects of positive endexpiratory pressure 0 n heart-lung interactions. J Crit Care 1991; 6: 1-11.

14 Apuzzo MJL, Wiess MH, Petersons V, Small RB, Kurze $T$, Heiden JS. Effect of positive end expiratory pressure ventilation on intracranial pressure in man. J Neurosurg 1977; 46: 227-32.

15 Johnson EE, Hedley-Whyte J. Continuous positive-pressure ventilation and portal flow in dogs with pulmonary edema. J Appl Physiol 1972; 33: 385-9.

16 Lantt WW, Greenway CV. Conceptual review of the hepatic vascular bed. Hepatology 1987; 7: 952-63.

17 Fujita $\Upsilon$ Effects of PEEP on splanchnic hemodynamics and blood volume. Acta Anaesthesiol Scand 1993; 37: 427-31.

18 Annat G, Viale JP, Bui Xuan B, et al. Effect of PEEP ventilation on renal function, plasma renin, aldosterone, neurophysins and urinary $\mathrm{ADH}$, and prostaglandins. Anesthesiology 1983; 58: 136-41.

19 Payen DM, Farge D, Beloucif S, et al. No involvement of antidiuretic hormone in acute antidiuresis during PEEP ventilation in humans. Anesthesiology 1987; 66: 17-23.

20 Fewell JE, Bond GC. Renal denervation eliminates the renal response to continuous positive-pressure ventilation (40599). Proc Soc Exp Biol Med 1979; 161: 574-8.

21 Priebe H-J, Heimann JC, Hedley-Whyte J. Mechanisms of renal dysfunction during positive end-expiratory pressure ventilation. J Appl Physiol 1981; 50: 643-9.

22 Hof RP, Hof A, Stürm RP. The Doppler method for measuring cardiac output in conscious rabbits: validation studies, uses, and limitations. J Pharmacol Methods 1990; 24: 263-76.

23 Haywood JR, Shaffer RA, Fastenow C, Fink GD, Brody $M J$. Regional blood flow measurement with pulsed Doppler flowmeter in conscious rat. Am J Physiol 1981; 241: H273-8.

24 Hartley CJ, Cole JS. An ultrasonic pulsed Doppler system for measuring blood flow in small vessels. J Appl Physiol 1974; 37: 626-9. 